\title{
Digital Infrastructure for Art Historical Research: thinking about user needs
}

\author{
Christina Kamposiori \\ Centre for Digital Humanities \\ Department of Information Studies \\ University College London \\ Gower Street, WC1E 6BT, London, UK \\ christina.kamposiori.11@ucl.ac.uk
}

\begin{abstract}
During the past years, the large technological advancements have provided research communities with applications and services never considered before. However, as the increased implication of the new technologies in the Arts \& Humanities have greatly affected the scholarly research process, the necessity to adapt digital tools and services to the needs of specific groups of researchers has considerably grown. The present paper aims to focus on the informational and methodological behaviour of art historians, so as to identify possible requirements for providing them with functional digital infrastructure. Hence, their research profile, their needs in terms of resources and the methodologies they employ should be examined. The emphasis, in particular, should be given in research activities with great value for art historical research, such as the information seeking and the collection of the required information objects. By supporting these first, stages of research with digital tools and services tailored to the needs of researchers would, actually, facilitate the whole research process in the field. Finally, this paper reports on research conducted for the author's current PhD Thesis "Personal Research Collections: examining research practices and user needs in art historical research", under the supervision of Prof. Claire Warwick and Mr Simon Mahony.
\end{abstract}

Art history. Scholarship. User needs. Information seeking. Collections. Digital infrastructure.

\section{INTRODUCTION}

In recent years, the rapid technological advancements and the proliferation of digital information objects have led to the growth of research conducted in digital environments. Though, especially in the field of the Arts \& Humanities, the capabilities developed by the new technologies have had a great impact on the scholarly research practices of its disciplines. In fact, these capabilities have affected the way scholars approach, create and manage information. Moreover, as digital initiatives have multiplied, so has the necessity to provide digital tools and services tailored to the needs of specific groups of researchers. More specifically, there is a rising need to study the informational and methodological behaviour of scholars, in order to create functional information systems which enhance scholarship in the Arts \& Humanities.

This specific need has been highlighted by several studies examining the scholarly research practices in the Arts \& Humanities and beyond. Brockman et al. (2001) examined the way researchers in the Arts \& Humanities work in the new information environment. Their argument was that, as new technologies bring changes to the behaviour and needs of scholars, it is important for the institutions, in that case the academic libraries, to adapt to the new circumstances. Palmer, Teffeau \& Pirmann (2009), based on Unsworth's concept of scholarly primitives, studied the scholarly activities and primitives in a variety of different disciplines, including in the Arts \& Humanities. Their aim was to report on the research process of scholars in different fields, make relevant comparisons and, therefore, provide useful information on the requirements needed for building effective digital infrastructure for scholarship.

Furthermore, various projects have dealt with the study of the behaviour and needs of scholars in the Arts \& Humanities. Rimmer et al. (2006), for instance, addressed in their paper issues based on work done for the User-Centred Interactive Search Project (UCIS). This project focused on the seeking behaviour of humanists in the new technological environment as well as in the more traditional ones, while its aim was to provide valuable information for the development of suitable resources which would facilitate the needs of scholars in the digital age. In 
addition, Benardou et al. (2009) in their paper, which reported on work conducted in the context of the European Project "Preparing Dariah: Preparing for the construction of the Digital Research Infrastructure for the Arts and Humanities", argued for the importance of developing a better understanding of the scholarly research process, in order to identify the requirements for providing scholars with appropriate tools and services for their research. For that purpose, they also presented a conceptual model of the scholarly research process based on the results of their research and interviews conducted with researchers from the Arts \& Humanities across Europe.

In the field of art history, in particularly, the research practices and behaviour of scholars have been until recently quite difficult to examine. Beeman (1995), being himself an original practitioner in the field, stated that art historians did not consider their daily work routine, their research practices and methods, as worth being studied and documented; thus, this notion made it considerably challenging for scholars and other information professionals interested in these activities to examine them. Regarding this difficulty, Carr (2006), also, argued that the way art historians work, which he considered to be rather complex and "untidy", was one more complicating factor. However, the arrival of the digital age brought a change in this attitude. The need, then, to adapt accordingly the scholarly research activities and methods used so far to the new information environment was considered essential (Beeman 1995, Grindley 2006).

Yet, the variety of resources needed for both research and teaching and the extensive set of methodological approaches employed by scholars make the application of the traditional research practices in the digital environment challenging (Beeman 1995, Reed 1992). In fact, these are both important issues to take into consideration when creating digital infrastructure for scholarship for the field. However, the profile of art historians as researchers and their different individual needs and expectations, based for example on different career stages or technological literacy, should be also seriously taken into account.

Understanding the significance that the first stages of research have for the smooth conduct of the whole research process, the present paper aims to focus on the information seeking activity of art historians, in terms of resources and methods used. This will be an attempt to contribute to the already fruitful discussion on the needs of researchers in the digital age and the possible requirements for constructing appropriate digital infrastructure for art historical research. Finally, the questions addressed and the information provided in this paper are based on research conducted for the author's in progress PhD Thesis, "Personal Research Collections: examining research practices and user needs in art historical research", which addresses issues on the information seeking of art historians and the building of their personal collections.

\section{INFORMATION SEEKING BEHAVIOUR IN ART HISTORY}

Generally speaking, it is difficult to identify and document with great detail and in their entirety the needs behind the behaviour of scholars in a field like art history, especially after considering a variety of factors which characterize the field. The wide range of information objects used for research and teaching, the extensive list of subjects studied and methods used, the different career level of scholars or their institutional affiliation are only some of the issues influencing their information seeking behaviour and, therefore, their needs. Moreover, in the digital age, the technological literacy of researchers and the extent to which scholars in art history employ the new technologies in their daily routine, along with the effect this choice has in their research, are some additional factors which make the construction of suitable digital tools and services tailored to their needs even more complicated.

Nevertheless, it seems that there is at some point a regular habitual behaviour researchers in art history have developed over the years, in terms of information objects and research practices (Bakewell, Beeman \& Reese 1988, Bailey \& Graham 2000). This observation, in conjunction with the examination of the possible effects the different factors can have in the work and the information seeking behaviour of researchers in the field, may result in a better understanding of their expectations and needs in the information age.

\subsection{Information objects in art historical research}

From the foundation of the discipline, art history has developed a close relationship with the art objects; art objects tend to play a key role in art historians' research even if they are not the central topic under examination. For instance, scholars researching on subjects such as artists' biographies, or subjects examining sociological, political or economic issues, but from an art historical point of view, will have at some point to deal with relevant art objects (Beeman 1995, Brilliant 1988, Bakewell, Beeman \& Reese 1988). Especially museums had a strong influence on the building of this relationship; however, this relationship may be subject to change. Art historians have expanded their interest to other 
forms of visual culture, whereas the "aesthetically superior" art objects have become a controversial source of knowledge (Durran 1997). Stam (1984), also, suggested that the way art historians approach the artworks during their study may vary depending on their institutional affiliation. More specifically, she proposed that academic art historians may be more interested in the examination of the historical background of an artwork, while scholars in museums in the physical aspects of the object. This observation may in fact prove valuable if we consider what needs these two categories might have, their similarities and differences, and how in fact we can "translate" the different approaches they employ towards the artworks in terms of tools and services in the digital age.

Although art objects play a principal role in art historical research, information objects in the field are not confined to artworks. Instead, they consist of an array of primary and secondary material, in various types and forms, which complement, substantiate or even sometimes replace the works of art. These can have textual, visual, or audiovisual format and can be either conventional or digital.

Regarding the conventional material, it includes textual resources such as monographs, books, journals and any other printed material relevant to research. The visual material needed, on the other hand, can be found in illustrated books, exhibition catalogues of museums and galleries, photographic archives, or other two-dimensional forms of representation, such as slides. Especially important for the field are the rare books and manuscripts and the visual material, which are considered necessary for the successful conduction of the research in art history. More specifically, these information objects acquire additional value if the original art object is lost or difficult to access, as well as when the research subject itself places the art object in a secondary role; for example, when the main subject is the biography of an artist (Brilliant 1988, Durran 1997, Bakewell, Beeman \& Reese 1988, Beaudoin 2005).

Considering the digital information objects, added to the more conventional ones, art historians tend to use mostly digital libraries and archives, databases with visual or other documentary material, digital journals and books, online thesaurus, indexes and dictionaries, as well as discussion lists, various sites and relevant blogs (Reed 1992, Durran 1997, Brilliant 1988).

Yet, it is widely known that scholars in the field still rely greatly on the conventional material for their research (Brockman 2001, Rose 2002). Digital resources are more likely to be treated as secondary material than to constitute the basic information objects. However, it can be easily acknowledged that this behaviour is more due to a habit and a feel of insecurity about new technologies than indifference about the possibilities they can offer. Harmsen (1996), moreover, argued that as the online material increases so will the level of importance that digital resources have for art historical research.

A similar attitude applies towards the original work of art and its digital surrogates. Actually, there is a strong desire to distinguish the original artwork from its reproductions (Promey \& Stewart 1997). Moreover, the emergence of digital surrogates has not managed to substitute the necessity to visit and examine the artwork in person (Bakewell, Beeman \& Reese 1988, Rose 2002, Beaudoin \& Brady 2011). In particular, as lack of access, poor quality and copyright issues are problems art historians have to face frequently when dealing with digital images, the physical examination of the object seems unavoidable (Durran 2007).

But, despite the difficulties met, digital surrogates obtain further value and can be treated as primary information objects if the original artwork is lost or inaccessible (Bakewell, Beeman \& Reese 1988). Also, they are valuable tools for publication and teaching in art history, as well as for the analytical method of iconology where the comparison between visual representations of art objects is the main concern (Beeman 1995, Brilliant 1988, Bakewell, Beeman \& Reese, 1988, Dallas 1998). Finally, the observation in Promey \& Stewart (1997) that students in art history, after having seen the digital surrogates of an artwork, were more excited to visit it in person, seems interesting and closely related to the discussion about the provision of digital surrogates by museums and the wish to visit the artworks in person.

\subsection{Art history and the seeking of information}

\subsubsection{The beginning of the quest}

According to Palmer, Teffeau \& Pirmann (2009) searching for research material can be a rather complicated activity for scholars; though, it is fundamental for the initiation of the research process. In art history, the beginning of the research process and, therefore, the seeking of the needed information, is to a great extent linked with the scholar's intuition and memory. These two qualities, which are associated with connoisseurship, apply especially on the case when research starts from the examination of the artwork. Brilliant (1988), for example, noted that scholars in the field, after relying greatly on their "visual memory" to examine a work of art, attempt to search for related information objects. 
In fact, artworks are sometimes what stimulate the initiation of the art historical research process, through enabling the discovery of the research subject and the generation of research questions. These questions, then, in combination with the experience of the researcher lead to the searching of the required material. According to Bailey \& Graham (2000), the types of information objects required each time in art history, as well as the way the research will continue, are determined by the research subject. Though, at this early stage of the research, Bakewell, Beeman \& Reese (1988) suggested that every possible resource may prove useful.

It seems then, as Bakewell, Beeman \& Reese (1988) reported, that works of art are "only the beginning of the quest". Still, while looking for information to support their research questions, art historians have to deal with a variety of difficulties. First of all, the diverse information objects they need are most times scattered all over the world. Thus, travel is an inevitable part of research and teaching in the discipline (Beeman 1995, Bakewell, Beeman \& Reese 1988). In the digital age, in particularly, the need to travel in museums and libraries around the world has not been replaced by the introduction of the digital information objects. Yet, it is important to mention that digitization of information and the provision of online access to it have considerably reduced the time to seek and discover the necessary resources (Rose 2002).

Regarding access to research material, it is an issue of grave concern for scholarship in the Arts \& Humanities, as it is a prerequisite for seeking and finding necessary resources. Since the level of creation and distribution of digital material in this area is lower than other fields, scholars face problems accessing the information they need. This problem of limited access to digital resources, which most disciplines in this area face, including art history, justifies to an extent researchers' preference to more conventional types of material, as well as the slower adoption of new technologies (Palmer, Teffeau \& Pirmann 2009, Dallas 1998, Brockman 2001).

In art historical research, in particularly, access to both textual as well as visual material is a crucial factor for the successful conduction of research. Reed (1992) observed that the available digital resources for art history cover mainly material dating from 1950 onwards, while there are few, or no digital resources for some subject areas, dating from before 1950. As a matter of fact, this finding is surprising, since it is well known that art historical scholarship strongly relies on the evidence of the past. Moreover, Durran (1997) stressed the existing need in the field to gather material scattered throughout the world in one place. She also mentioned the need to deal with copyright issues, so as these resources can become truly accessible. On the other hand, Rose (2002), through her research, found out that, in comparison with the past, the need for access to digital libraries has been to an extent covered. However, scholars' wish to access more visual material of high quality and resolution has not been satisfied yet. Similarly, Greenhalgh (2004) claimed that art historians' aspiration of easier access, seeking and discovery of the essential visual resources has not been fulfilled.

\subsubsection{Information seeking activities in art history}

Despite access difficulties, art historians seem to more or less engage with digital tools and services when they search for information. Search engines, in particular, are considered by art historians a useful tool for research (Grindley 2006, Vaughan, 2003, Harmsen, 1996). Considering the most important data in art history, they are the names, titles, places and dates referring to works of art (Reed, 1992). Accordingly, Bates, Wilde and Siegfried (1993), in their study for the Getty Online Searching Project, confirmed the use of these terms during the seeking process in the Arts \& Humanities.

However, the use of specific search terms is usual when the target is clearly defined, so that familiar terminology can be used within the search engines of databases or other relevant sites. Direct searching, though, requires precision in the use of terminology. Otherwise, misspelling or incorrect terminology may result in an ineffective search, especially when it is conducted in large information retrieval systems (Greenhalgh 2004). Also, information seeking may be proved problematic when searching in non specialist search engines, such as Yahoo and Google (Rose 2002).

But, although direct searching is a possibility in art history, it is not usually chosen by scholars as an effective searching activity. Instead, chaining and browsing are the information seeking activities most preferred in the discipline. In fact, these are two of the main reasons Beaudoin (2005) argued that art historians' information seeking behaviour matches Thomas Mann's "Subject or Discipline Model" and "Library Science Model" of information seeking, as well Marcia Bates' "berrypicking" searching model. According to these models, among some of the characteristics fitting art historians' information seeking behaviour are the great reliance on libraries for browsing material and the use of bibliographies, citations, indexes and abstracts for tracking resources.

To begin with, chaining is a significant seeking activity in art historical research and it is usually carried out through, for example, books, articles, 
bibliographic catalogues, references and footnotes. Brilliant (1988) described effectively this activity in his paper.

Every scholar begins research with known bibliographical sources and moves from known sources to the unknown through the references, the footnotes, and the bibliography provided by the source.

In addition, art historians prefer to use chaining not only for finding relevant research material, but also for staying up to date with the latest news in their field (Brilliant 1988, Reed 1992, Bakewell, Beeman \& Reese 1988). Particularly in the digital environment, various databases, like indexes and online catalogues, have been designed to meet these specific needs (Reed 1992, Dallas 1998, Bakewell, Beeman \& Reese 1988). Hence, many scholars appreciate the fact that this activity can be conducted faster in the digital environment, while it also provides them with the ability to print search results. Reed (1992), for instance, mentioned that many art historians are not keen on going through volumes of printed books and articles to find relevant footnotes and references, since this activity has become much quicker with digital tools. This statement, in fact, demonstrates an important progress in the previous sceptical stance art historians used to hold regarding new technologies.

Several studies have referred to browsing as an activity extensively encountered in art history (Reed 1992, Bakewell, Beeman \& Reese 1988, Durran 1997, Challener 1999). This activity, as Palmer, Teffeau \& Pirmann (2009) observed, differs from the other information seeking activities.

Browsing tends to be open ended with the searcher looking through a body of assembled or accessible information.

In art historical research, browsing has been traditionally conducted in libraries around the world. That is because printed versions of books and journals are in a great degree suitable for browsing and easy to use (Brockman et al. 2001). Considering the information age, digital databases of potential interest are preferred for browsing digital material. It is significant, though, that browsing through digital libraries is conducted many times with relevant success. Art historians usually find more interesting the results they get through browsing online material, than those they find through more conventional resources (Reed 1992). Since browsing, as an information seeking activity, enables "serendipitous discovery" to happen (Palmer, Teffeau \& Pirmann 2009, Dallas 1998), digital tools and services can enhance this possibility. However, attention is needed regarding the issue of "grey" resources usually met in the online environment (Dallas 1998); for example, resources written by amateurs for the general interest or educational purposes.

On the other hand, Challener (1999) argued that, if a digital library is not designed to meet this specific need of researchers in art history, various problems are likely to be encountered. For instance, it is well known that art historians are especially interested in browsing databases containing digital surrogates of artworks; indeed, they are one of the primary places of interest for searching visual material. But, although they consider them to be very useful, Durran (1997) found out that they scholars complained about the time-consuming process of seeking through a large number of digital surrogates. Therefore, in her research, scholars emphasized the importance of an initial limitation of results to help them find information relevant to their research.

However, the activities mentioned until now are not the only used in art history for finding essential research material. First of all, the scanning or, otherwise, skimming of textual resources, which usually takes place while browsing both in physical and digital environments, leads to the evaluation of a resource as relevant or not to a research subject (Palmer, Teffeau \& Pirmann 2009, Brockman 2001). Consequently, it is possible that scanning may result in the discovery of useful information not known before (Brockman et al. 2001).

Moreover, networking and communication are valuable activities in the Arts \& Humanities for various reasons. One of them is their efficiency in finding resources of potential interest. Informal communication with colleagues and other subject specialist, exchanging information in conferences and other types of meetings, as well as visiting publishers in person are some of the most useful ways for discovering resources in art historical research and keeping track of the progress in the field (Reed 1992, Bakewell, Beeman \& Reese 1988, Challener 1999, Grindley 2006, Rose 2002, Kamposiori \& Benardou 2011). Stam (1997), specifically, referred to the communication between colleagues in the field as the "invisible college", constituting an important part of the information seeking behaviour of art historians. Being in the digital age, these activities are supported by a range of tools and services. E-mail, discussion lists, forums, blogs, online conferencing services are some of the digital tools and services enhancing these activities and, thus, scholars' information seeking activity (Beeman 1995, Dallas 1998, Grindley 2006).

Lastly, although some similarities in terms of the information seeking behaviour of different groups of art historians can be identified, there is a growing need to further examine some specific groups, 
whose their needs and methods have been until now understudied. For example, the fact that scholars researching on interdisciplinary or nontraditional subjects confront difficulties while seeking for information, demonstrates that their methods and needs lack thorough examination and support (Rose 2002). Therefore, in order to provide them with personalized tools and services for their research, it is essential to identify and understand the differences in the research methods and interests. Finally, it is important to study not only the more profound searching activities that scholars employ, but also other research activities which may facilitate their information seeking activity. Their support with appropriate digital infrastructure, then, will enhance art historical research as a whole.

\subsection{Collecting and organising data}

The collection of information while searching is a usual activity for many scholars during research (Palmer, Teffeau \& Pirmann 2009). In art history, data collection is a research activity of grave significance and, for that reason, conducted by all scholars in the discipline (Challener 1999). As a result, the present paper suggests that collecting in art historical research can be considered as an "attached" activity to information seeking; thus, it should be examined together and enhanced with the appropriate digital infrastructure after identifying the needs and expectations of researchers. This observation can be better understood after considering a number of reasons.

Firstly, difficulties during information seeking, the possible lack of access to resources, the limited documentation available for some research subjects and copyright issues are only a few of the problems scholars have to face regularly when they search of information. In such cases, the establishment of personal collections seems, indeed, as a highly advantageous solution. For instance, according to Grindley (2006), gathering, especially, visual reproductions of art objects may constitute a solution to problems such as copyright issues, incompatibility of metadata, duration and robustness of digital objects. Also, both Durran (1997) and Bakewell, Beeman \& Reese (1988) referred to the insufficient image collections of many museums and galleries, the lack of visual material for some art periods and the difficulties faced during searching for it online. Moreover, Brockman et al. (2001) observed that the gathering of research material and the establishment of collections are not only preferred for easier access to resources, but also for the ease in making printed copies, a convenient solution for travel. Thus, it is not surprising the fact that some studies have noted the pride many researchers feel for their collections (Palmer, Teffeau \& Pirmann 2009, Brockman et al. 2001).

Additionally, collections of data are established for satisfying a number of other research activities. Palmer, Teffeau \& Pirmann (2009) argued that collections in the Arts \& Humanities are greatly related to the activity of reading, as well as to the primitive of rereading. They also found out that collecting material helped researchers stay up to date with the developments in their area of study. Furthermore, the exchange of personal collections could solve other researchers' information seeking problems and enhance collaboration; however, up to now, there has not been much willingness to share them (Palmer, Teffeau \& Pirmann 2009, Kamposiori \& Benardou 2011).

Yet, particularly digital collections seem not only to facilitate other activities, but also, to an extent, they "encapsulate" them in their environment. For example, since they form an archive of information, they involve many research activities such as the seeking of information, browsing, reading or annotating. But, in contrast to the institutional databases used often by scholars, personal collections can be built and managed upon personal criteria (Palmer, Teffeau \& Pirmann 2009, Bakewell, Beeman \& Reese 1988). The ability to keep whatever is considered useful and organise it according to personal interests can have a positive effect on other research activities, such as to enable the easier searching throughout the database or allow the effective comparison between digital surrogates.

Digital collections, however, raise issues of creation, design, use and management of digital resources. For example, as collections grow, so does the need for their curation (Palmer, Teffeau \& Pirmann 2009). But in order to effectively support art historians with the appropriate digital infrastructure, it is essential to understand their collecting and organising behaviour. First of all, an interesting point made by Palmer, Teffeau \& Pirmann (2009) is that research collections in the Arts \& Humanities tend to consist more of documents rather than raw data. Moreover, Brockman et al. (2001), based on their research results, noted that scholars in the Arts and Humanities do not have any systematic way or patterns for gathering their material. As for art historical research, data collection regards mostly the primary and secondary material scholars manage to gather during research. In general terms, the gathering of data regards everything that could be of importance for both current and future research, with a preference to primary material.

Concerning the organization of information, it is essential to mention at this point that the majority of 
art historians still use file cards and other traditional methods, like notebooks, to store and organise the material they collected over the years for research and teaching (Bakewell, Beeman \& Reese 1988, Reed 1992). Rose (2002), through her research, discovered that art historians were not enthusiastic about the use of a computer for storing and organising their data. After comparing her results with those of the user study conducted by the Getty Art History Information Program in 1986, she found out that, although art historians' wish to access digital archives through their computers was to a great deal fulfilled, computers were still not preferred for storing and organising information.

It is not surprising, though, that art historians tend to feel more comfortable in using more traditional methods, as new technologies have still not succeeded to satisfy their needs. For instance, Battin \& Stam (1989) referred to the complaints made by researchers in art history about the difficulties faced while organising their textual and visual material in their digital collections. Since the existing systems did not meet their needs, they found it rather difficult to stop using the methods they were accustomed to. Similarly, according to Palmer, Teffeau \& Pirmann (2009), even if scholars in their study chose to use at some point computers and digital tools for keeping their files, they tended to keep the conventional material as well due to fear of data loss.

One possible explanation to this difficulty that computers have in satisfying the storing and organisational needs of art historians in the digital age may be the many personalised ways scholars tend to use for these practices. For example, some scholars prefer to organise their bibliographic references separately to save time, whereas they tend to organise their visual material based to specific needs and purposes, such as research or teaching (Bakewell, Beeman \& Reese 1988). Moreover, others prefer to organise their resources according to finished or unfinished projects (Bakewell, Beeman \& Reese 1988).

For that reason, Borgman (2007) argued that the tools provided to support the organisation of information should reflect the practices followed in the real word. Beeman (1995), on the other hand, suggested that, when systematic filing systems are used, there are two factors that should be taken under account. Their "organic quality" and the fact that art historians usually tend to organise their files according to projects and not under a master file. Additionally, Bakewell Beeman \& Reese (1988) argued that the ideal digital organisation system for art history would allow the integration between the various files of the collection, textual and visual. This observation indeed, could enhance art historical research as well as teaching and publishing in the field. Finally, it is as important to train researchers to use these systems, as it is to provide them with the appropriate digital infrastructure. Otherwise, the engagement with unfamiliar tools and services may result in one more time-consuming and disappointing experience for them.

\section{CONCLUSION}

To conclude, the aim of this paper was to address important issues regarding the information seeking activity of art historians in the digital age. It suggested that special attention should be given to the needs of different groups of researchers in the field, while it attempted to give an overview of the information objects and information seeking activities employed by scholars. Also, it emphasised the significance of the collecting activity in art history and mentioned the growing need to support this activity with digital tools and services tailored to the personalised needs of researchers. Actually, the understanding of the research practices at these first stages of research, along with the problems faced, can lead to observations useful for enhancing the whole research process in the field. Identifying the needs behind the behaviour of scholars would result in the construction of more cost-effective and efficient digital infrastructures for research.

\section{REFERENCES}

Bailey, C. \& Graham, M.E. (2000) The Corpus and the Art Historian. Thirtieth International Congress of the History of Art. Art History for the Millenium: Time, London, UK, 3-8 September 2000. International Committee for the History of Art (CIHA). http://tiny.cc/0oi7bw (retrieved 10 November 2009).

Bakewell, E. et al. (1988) Object, Image, Inquiry. The art historian at work. J. Paul Getty Trust, United States of America.

Bates, M.J., Wilde, D.N. and Siegfried, S. (1993) An Analysis of Search Terminology Used by Humanities Scholars: The Getty Online Searching Project Report Number 1. The Library Quarterly, 63 (1), pp. 1-39.

Beaudoin, J.E. and Brady, J.E. (2011) A Study of Image Resources Used by Archaeologists, Architects, Art Historians, and Artists. Art Documentation: Journal of the Art Libraries Society of North America, 30(2), pp. 24-36.

Beaudoin, J. (2005) Image and Text: A Review of the Literature Concerning the Information Needs and Research Behaviors of Art Historians. Art Documentation: Journal of the Art Libraries Society of North America, 24(2), pp.34-37. 
Beeman, A. (1995) Stalking the Art Historian. In Shields, M.A. (eds). Work and technology in higher education: the Social Construction of Academic Computing. Routledge, USA, pp. 89-102.

Benardou, A., Constantopoulos, P., Dallas, C. and Gavrilis, D. (2009) Understanding the Information Requirements of Arts and Humanities Scholarship. 5th International Digital Curation Conference, London, UK, 2-4 December 2009.

Borgman, C.L. (2007) Scholarship in the Digital Age. Information, Infrastructure and the Internet. The MIT Press, United States of America, pp. 3345.

Brilliant, R. (1988) How an Art Historian Connects Art Objects and Information. In Stam, D.C. \& Giral, A. (eds). Linking Art Objects and Art Information. Library Trends 37(2), pp. 120-129. http://tiny.cc/qcf7bw (retrieved 20 April 2010).

Brockman, W.S., Neumann, L., Palmer C.L. and Tidline, T.J. (2001) Scholarly Work in the Humanities and the Evolving Information Environment. Digital Library Federation and Council on Library and Information Resources, Washington, D.C.

Challener, J. (1999) Information-Seeking Behavior of Professors in Art History and Studio Art. Master's Research Paper. Kent State University, United States. http://tiny.cc/dff7bw (retrieved 14 July 2010).

Dallas, C. (1998) Humanistic Research, Information Resources and Electronic Communication. Panteion University Library, Athens, Greece. http://tiny.cc/gef7bw (retrieved 10 October 2009).

Durran, J. (1997) Art History, Scholarship and Image Libraries: Realizing the Potential of the Digital Age. http://tiny.cc/raf7bw (retrieved 24 November 2009).

Greenhalgh, M. (2004) Art History. In Schreibman, S., Siemens, R. and Unsworth, J. (eds). A Companion to Digital Humanities. Blackwell Publishing, Oxford. http://tiny.cc//9e7bw (retrieved 22 July 2009).

Grindley, N. (2006) What's in the Art-Historian's Toolkit? A Methods Network Working Paper, AHRC ICT Methods Network. http://tiny.cc/nkg7bw (retrieved 9 November 2009).

Harmsen, L. (1996) The Internet as a Research Medium for Art Historians. The Art History Research http://www.harmsen.net/ahrc/essay.htm (retrieved 7 August 2009).

Kamposiori, C. \& Benardou, A. (2011) Collaboration in Art Historical Research: Looking at primitives. Kunstgeschichte, Open Peer Reviewed Journal. $\quad$ http://www.kunstgeschichteejournal.net/157/ (retrieved 17 June 2011).

Palmer, C.L., Teffeau, L.C. and Pirmann C.M. (2009) Scholarly Information Practices in the Online Environment. Themes from the Literature and Implications for Library Service Development. Report commissioned by OCLC Research. www.oclc.org/programs/publications/reports/200902.pdf (retrieved 16 January 2010).

Promey, S. M. and Stewart, M. (1997) Digital Art History: A New Field for Collaboration. American Art, 11(2), pp. 36-41.

Reed, M. (1992) Navigator, Mapmaker, Stargazer: Charting the New Electronic Sources in Art History. Library Trends, 40(4), pp. 733-755.

Rimmer, J., Warwick, C., Blandford, A., Gow, J. and Buchanan, G. (2006) Humanities Scholars' Information-seeking Behaviour and Use of Digital Resources. DL-CUBA 2006, Workshop on Digital Libraries in the Context of the detailed design of the system interface influences behaviour, Chapel Hill, USA, 15 June 2006.

Rose, T. (2002) Technology's Impact on the Information-Seeking Behavior of Art Historians. Art Documentation, 21(2), pp. 35-42.

Stam, D.C. (1997) How Art Historians Look for Information. Art Documentation: Journal of the Art Libraries Society of North America, 16(2), pp. 2730.

Stam, D.C. (1989) Art Historians and their Use of Illustrated Texts. In Scholarly Resources in Art History. Issues in Preservation. Report of the Seminar. Spring Hill, Wayzata, Minnesota, September 29 - October 1 1988. Commission on Preservation and Access, Washington, D.C, pp. 927.

Stam, D.C. (1984) The information-seeking practices of art historians in museums and colleges in the United States. PhD Dissertation. Columbia University, United States.

Vaughan, W. (2003) History of Art in the Digital Age: Problems and Possibilities. Zeitenblicke, 2(1). http://tiny.cc/pbt7bw (retrieved 3 March 2010). 